\title{
From patient to parent: a dual-generation journey
}

Cite as: CMAJ 2019 October 21;191:E1165-6. doi: 10.1503/cmaj.190524

CMAJ Podcasts: audio reading at https://soundcloud.com/cmajpodcasts/190524-enc

W

orry, fear, guilt, relief. These are just some of the emotions any parent of a child with a serious illness has felt at some point in their journey. But what about when history is repeating itself, and not only are you the parent, but at one point you were also a child with the same diagnosis? Jan. 15, 1993, was a pivotal day. After almost a year of active symptoms, I was diagnosed with Crohn disease. I was nine years old. Fast-forward to Jan. 10, 2019, at the same hospital. My daughter was diagnosed with Crohn disease. She was 11.

Our destinations were the same, but we had two very different journeys. Before my diagnosis, I was in constant pain, had severe gastrointestinal symptoms and overall was the epitome of a "sick child." Ava was not in pain, had no gastrointestinal symptoms and was functioning like her peers. What she was not doing was growing. She had gone over one year without any growth at all and, being petite to begin with, had straight-lined right off the growth curve. She was nearly 11 years old but the size of an average eight-year-old. Her clothing size had not increased in almost three years; she wore shoes out rather than outgrowing them. Ava was not overly active, but I attributed this to her creative spirit; she preferred to draw or read over playing sports. Then there were her fevers: regular, reoccurring fevers in the evening, from low grade to $102^{\circ} \mathrm{F}$. These fevers had been happening for months, with no pattern or explanation. She was initially referred to endocrinology, but after her initial blood tests came back showing very low hemoglobin and iron levels, she was then referred to hematology. And our journey began.

After no response to months of a high-dose daily iron supplement and with no abnormalities in growth hormone production or genetic testing, both specialists knew something else was causing the deficiencies. Our next referral was to gastroenterology, which I felt was wasting valuable time; I wanted her to get to rheumatology first, which was also on the table. As someone who had lived for 25-plus years with Crohn disease, of course I would know if my own child had something similar, wouldn't I?

Within weeks of our initial gastroenterology appointment, Ava had a colonoscopy and endoscopy under a general anesthesia. At home, the prep for these scopes was Ava's breaking point. After months of bravely enduring multiple tests and

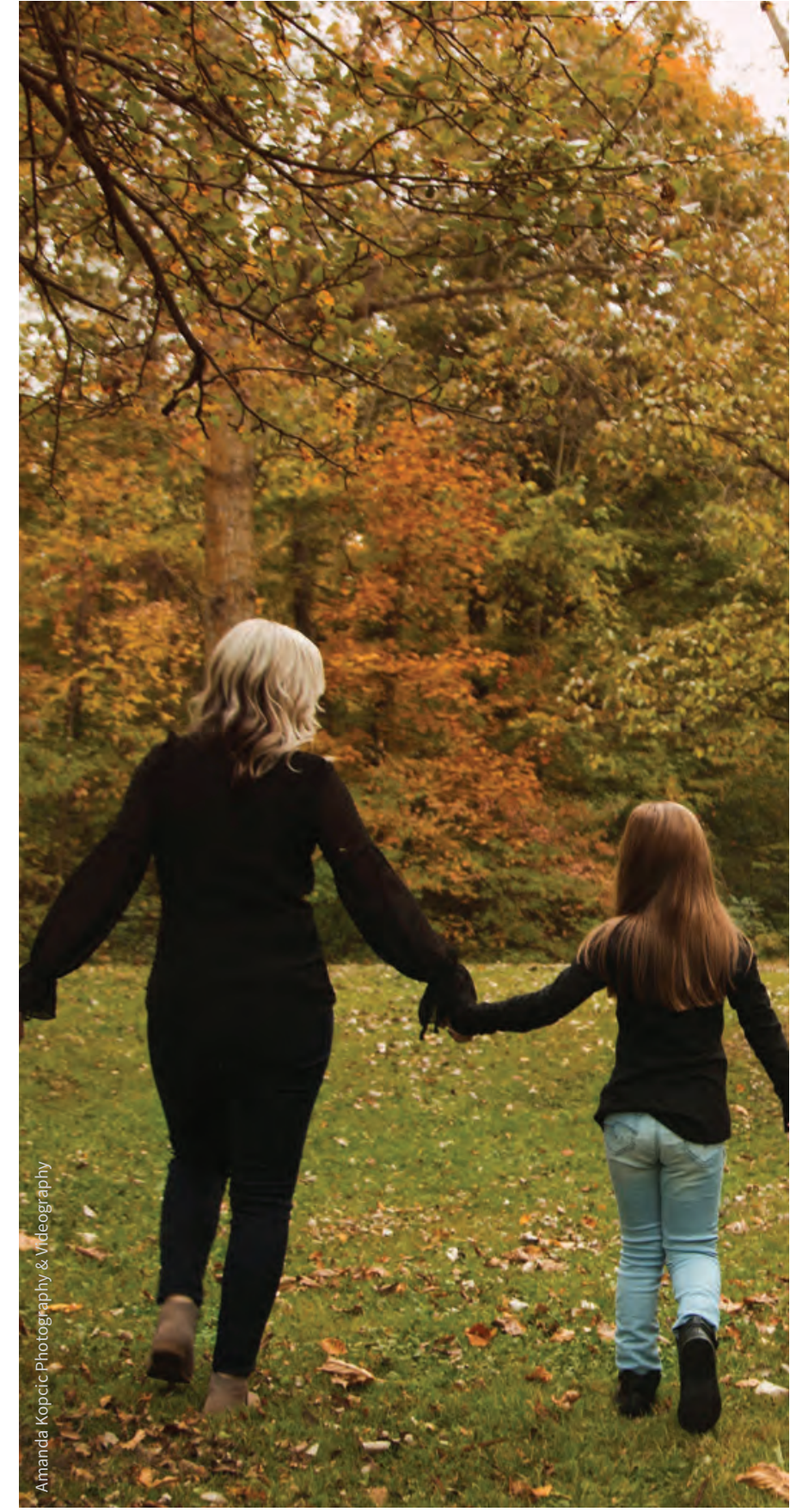


countless rounds of blood tests, she sobbed in my arms, just wanting it to be over, and my heart broke. The next morning, I held her hand and watched her small body relax as she drifted out of consciousness. The results were conclusive: there was so much active disease she was diagnosed on the spot. I couldn't believe it: I had been so wrong. What did that say about my maternal instinct?

Suddenly I was swimming in emotions: relief that we finally had an answer, guilt that I had so adamantly refused to think the problem was gastrointestinal and worry over what would happen next. Within two years of my own diagnosis, I had undergone a bowel resection; I have a six-inch scar across my abdomen as a souvenir. I missed so much school I had a full term with no grades. I had been on such high doses of prednisone that I'm unrecognizable in some school pictures from the bloating. I remember once going back to school after being off sick, and a random child asking if I'd gained weight because my face was so round and full.

For Ava, the diagnostic procedures were not done yet; we followed up with magnetic resonance enterography (MRE) to explore the small bowel. It was not as upsetting for Ava and she even enjoyed the drink. The challenge was that I was not able to enter the MRE suite because of the staples in my bowel from my resection. This was difficult for us both. We returned to the gastroenterologist a few weeks later to discuss Ava's treatment plan. I was so confused - I had no idea what any of these options were. I had been managing my symptoms reactively for years, and luckily had not needed any testing in more than a decade and had not seen a gastroenterologist since mine of more than 20 years had retired. I had no idea what biologics or exclusive enteral nutrition were. Suddenly, I wasn't such a know-it-all; in fact, I was clueless and overwhelmed.

We were trying to include Ava in as much of the decision-making as possible. One option for a biologic treatment was infliximab infusions, which would start with every two weeks and eventually decrease to once every eight weeks - but would essentially be a full day at the hospital each time. The alternative was adalimumab injections, done at home every other day. As a working parent, I thought the convenience of an at-home treatment was appealing - but the idea of regular injections was extremely distressing to Ava. With assurance by the doctor that at this stage there was no superior treatment, Ava's wishes were the deciding factor - infliximab it was, along with weekly methotrexate and folic acid, and continuing iron and vitamin D supplements. After just one infusion, the change in her appetite was noticeable, and after two infusions, she had grown, gained weight and had increased energy levels. Every infusion since has resulted in improvements; the fevers have almost completely stopped and finally her iron level has started to increase. We do at-home fecal calprotectin testing ahead of each infusion; when we got to the six-week stage, the results showed a spike in inflammation, so currently Ava is receiving infusions every four weeks. She will have another scope in the future to analyze the internal effects.

When I was young, it was so rare to meet another child with Crohn disease - now I am amazed at the number of children we see receiving infusions, and how much bigger the pediatric gastroenterology department has become. In fact, a few months after Ava's diagnosis, we learned our neighbours had been going through the same process, and their daughter was also diagnosed with Crohn disease. This has created a unique bond between the girls. The speed at which Ava was diagnosed is a testament to the advancement in understanding this disease. She has missed fewer than 10 days of school since receiving her diagnosis.

Going from patient to parent is a complex journey. On one hand, it's easy to think you have more knowledge and, in my case, to think you know everything - only to learn quickly that's not the case. On the other hand, as any parent of a sick child would, you worry - but as the one who was also a sick child, you start to relive every test, every adverse effect and every setback. At our first appointment, when Ava's gastroenterologist said she thought it was Crohn disease, I was visibly emotional. Not because of the disease, but because at that moment all I could think about was my childhood experiences - the thick, chalky tasting barium swallow test, the barium enema that still to this day I cannot think about, because even more than 26 years later I still remember it vividly, the pressure and the discomfort as my mom tried to console me. My bowel resection: spending 12 days in the hospital while my mom slept on a cot, the gagging reflex as they pulled the nasogastric tube out through my nose when I was finally cleared to consume liquids on my own.

Even if you had 100 positive experiences and only five negative ones, all you think about is your child having those negative experiences. You want to take it all away, even if it means going through it all again. Suddenly the appreciation I had for my own mom was abundant. When you are nine, you don't think about your parent missing work, the emotions involved, how keeping track of appointments, tests, prep and medications becomes a part of life. You don't think about the costs, such as missed work, gas, parking, lunches at the hospital, medications and supplements that may not be covered. All you think is that your mom is there to take care of you, and that makes it all okay. I hope that's how my daughter feels. I hope she thinks, Mom is here. Mom has this too. Everything will be okay.

\section{Shannon Cushman}

Strathroy, Ont.

This article has been peer reviewed.

Acknowledgement: The author dedicates this article to her mother. "Thank you, Mom, for making everything okay."

This is a true story. Ava has read the article and given her consent to have it published alongside the photograph. 